lay there for a month, without having recourse to medical aid, although during the greater part of the time she suffered severely. Within a day or two after leaving her bed, at the moment of rising from a chair, she felt a sensation of something having suddenly given way; and she found that her clothes, and the floor beneath, were deluged with a fluid of watery appearance. From that time she lost all power of retaining her urine.

Mr. Crookes saw her on July I 2 th, I844. The vagina, as she lay in bed, was found to be full of urine; the mucous membrane was superficially ulcerated in irregular patches, and encrusted generally with the salts of the urine. An inch, or rather more, from the ostium vaginæ, and on the upper surface, there was an opening through which the urine could be seen trickling, and escaping in little gushes whenever the abdominal muscles were suddenly called into action. A full-sized male catheter passed through this opening, with perfeet ease. The margins of the opening were irregular and thickened; the lower or posterior border was especially thick and fleshy, and presented on its under surface three irregularly triangular mamillary projections, which were excoriated and acutely sensitive. With a view of tracing the relation of this opening with the internal orifice of the urethra, Mr. Crookes proceeded to pass a catheter by the urethra into the bladder. The meatus urinarius, however, could not be found ; and, on closer inspection, it was evident that the whole tract of the urethra had disappeared-its ordinary course presenting nothing but a smooth uniform mucous surface. The opening in the vagina was, in fact, the natural opening into the bladder at its point of junction with the urethra; and the irregular and fleshy margin was composed of the thickened fragments of that canal, or the neck of the bladder.

July 16. Under the sanction of Mr. Perry, Inspector of Prisons, and in the presence of the late Dr. Baly, Mr. W. A. Sumner, and myself, Mr. Crookes performed the following operation. The patient was placed upon a table, and tied in the ordinary position for lithotomy; and Beaumont's speculum was introduced into the vagina. By this instrument a good view of the parts was obtained, and space procured for the necessary manipulation. The state of the vagina was found to be much improved since the former examination, the calcareous matter having been almost wholly removed by the assiduous attention of a good nurse. When the blades of the speculum were fully expanded, and the opening into the bladder fully exposed, it was seen to be transverse in direction, somewhat of a half-moon in shape, less defined in its lower or posterior border than in the anterior or upper, and rather more than an inch in transverse measurement. Through this opening, when fully distended by the speculum, the inner surface of the bladder was visible, and the orifices of both ureters could be clearly seen distilling the urine.

By slow and cautious steps, the edges of the opening were pared away completely, and a thorough abrasion of the surface effected. This part of the proceeding proved to be extremely tedious and wearisome. More blood was lost than was anticipated; and the necessity for constantly clearing the vagina from the accumulated clots and urine added much to the length of the operation. The edges being sufficiently pared, two double sutures, introduced without much difficulty by means of Beaumont's needle, .enabled Mr. Crookes to bring the parts together, and they adapted themselves in the way desired most completely. A small-sized gum elastic catheter was then passed into the bladder, and the patient laid upon her back in bed. The instrument was secured in its position by tapes; and, a folded draw-sheet having been placed beneath the buttocks, the urine was allowed to dribble away as soon as it entered the bladder. The operation lasted altogether for about two hours; and, although tedious, the patient did not appear to suffer pain. The bowels were subsequently kept in a free state by the use of castoroil, and no unfavourable symptoms occurred. On the third day the sutures were removed. The catheter was kept in the bladder till the tenth day. The vagina was cautiously syringed out with warm water several times daily; and every attention was paid to keep the parts in a quiet and cleanly condition.

Three weeks after the operation the surfaces were found to have united perfectly, and a thick and short portion of urethral canal was thus formed. The incontinence of urine, however, still continued. The use of a sponge pessary was now tried, in the hope that, by pressure on the newly formed portion of the urethra, the flow of urine might be in some measure controlled. The pressure of the pessary was completely efficacious. The bladder became capable of retaining urine until the patient felt a desire to pass it; and a slight change in the position of the pessary enabled her to relieve the bladder of its contents at will. Her clothes, and the cell in which she was confined, lost their former urinous odour; and she was enabled to mix among the other prisoners, and take the usual exercise with comfort. After wearing the pessary for several weeks, she began to find that she could retain a portion of her urine without its use; and in a short time afterwards that she could dispense with it altogether. In accordance with the terms of her sentence, she was afterwards removed to one of the penal colonies; and at the time of her removal she was wholly free from any trace of her former loathsome affliction.

REMarks. The notes of this case were taken at the time of the operation, and while the patient was under treatment-now twentythree years ago. Mr. Crookes, having changed his residence, and moved his books and papers more than once since he retired from the practice of the profession, had lost sight of them until lately. With his concurrence I now send them for publication.

Sudden local violence of an unusual character-a single blow, as in this case-though one of the possible causes of a fistulous communication between the bladder and vagina, has been less frequently so, than the pressure caused by delay of the child's head-perhaps of unusual size-in lingering labour. In this case the whole of the urethra had perished by sloughing as a consequence of the injury.

The instruments used in the operation were obtained from Messrs. Ferguson, of Giltspur Street. The speculum vaginæ, as well as the needle, had been made under the direction of Mr. Beaumont of Toronto, when residing in London. The speculum consists of several small blades, which can be fixed separately by screws at the distance required. One great advantage of the instrument is, that it can be kept in place without the help of an assistant. A common scalpel and dissecting forceps were used for paring the edges of the wound; and the silk thread in general use for ligatures was taken for sutures. A large brass syringe was found the most convenient instrument for keeping the vagina clear during the operation. The patient was not a very tractable subject; and she com. plained more than once of the length of time she was kept in a constrained position; but she did not complain of the pain caused by any of the steps of the operation.

\section{CASE OF DOUBLE OVARIOTOMY.}

\section{By JOHN WALTERS, M.B., Reigate.}

H. S., aged 40, a pale thin woman, was admitted into the Reigate Cottage Hospital on September 3 rd, 1867 , suffering from ovarian disease. She had always had good health, though her family are phthisical. She had been married four years, and had one child three years old. Her abdomen began to enlarge after her confinement, and had continued to do so ever since. The catamenia were regular up till February last, when she had had only a slight show. In July last, she was tapped by Dr. Braxton Hicks, in Guy's Hospital, and eighteen pints of clear fluid were removed, disclosing, as Dr. Hicks kindly informed me, a large mass of secondary growths, with, probably, adhesions on the left side, near the position of the spleen.

On admission, the abdomen was greatly distended, measuring fortyone inches at the umbilicus. There was evidently a large cyst in front, and a mass of more solid material behind. In the region of the uterus was a large solid mass, moving with that organ, and giving the impres. sion of a fibroid uterine tumour. The whole tumour seemed to move pretty easily. She suffered much from the weight and size of the tumour, and was very anxious to have it removed. The urine was natural, and there was no evidence of disease in the chest.

On September 5th, having obtained the kind assistance of Mr. Christopher Heath, Mr. Kelsey, of Redhill, and my partners, Dr. Holman and Mr. Hallowes, and chloroform having been administered by Mr. Kelsey, I made an incision below the umbilicus, of four inches in extent. On opening the peritoneur., a large quantity of ascitic fluid escaped. A large cyst was then tapped; and the cyst-wall was seized with forceps and drawn forwards. The tapping of two other cysts followed; but this did not diminish the tumour sufficiently to allow of its extraction without enlarging the wound. This was accordingly done, and the mass gradually withdrawn; slight adhesions were torn through on the right side, and on the left a strong band required division with the clamp cautery. The pedicle, which was long and thin and was attached to the left side of the uterus, was then secured with a clamp and divided. On examining the right ovary, it was found to be distended into a single cyst of the size of a bladder. This was readily withdrawn; and the pedicle, of moderate length, secured with a second clamp above the other. The uterus was healthy. The peritoneum was thickened and velvety. The wound was closed with silver sutures, including the peritoneum, and an opium suppository introduced. She recovered well from the shock of the operation and the chloroform, and passed a pretty comfortable night, having very little sickness, and took a fair amount of nourishment-beef-tea and milk, etc., with brandy. The catheter was passed every six hours. 
On September 6th, in the morning, the pulse was 110; temperature, 100.5 deg. She felt comfortable, and had no pain or sickness. The urine was scanty and high coloured. At II P.M., the pulse had gone up to I26. She was very hot; the temperature remaining the same. She had been sick several times, and suffered from flatulence. She was ordered ice to suck, beef-tea, arrow-root with brandy, and champagne; and an opiate injection.

September 7 th, 6 A.M. Pulse 134; temperature, $99 \frac{7}{8}$ deg. She had dozed a good deal ; there was no sickness. She complained much of flatulence.--6 P. M. Pulse 140; temperature, ${ }^{\circ} 98.5 \mathrm{deg}$. She had cold perspirations and a great deal of flatulence, and was very restless. She was ordered to have egg and brandy, beef-tea, and beef-tea and brandy injections. The urine was very scanty and high coloured. The opiate injection was ordered to be repeated.

September 8th. Pulse about 140; temperature, $99 \frac{1}{8} \mathrm{deg}$. She was very restless, and suffered much from flatulence. She seemed sinking. She was ordered to have as much nourishment and brandy as could be got down ; and turpentine fomentations to the abdomen. A long tube was introduced into the sigmoid flexure, but failed to relieve the flatulence. The upper clamp (right) was removed, as there seemed a good deal of tension on it from the enormous distension of the abdomen.

Towards evening, she became very restless, and was cold and clammy, with a scarcely perceptible pulse. From her constant movement, some hæmorrhage occurred from the right pedicle; to check which it was necessary to reopen part of the wound. She became rapidly worse after this, and died at 7 P.M.

On opening the wound after death, the surface of the intestines was found injected and roughened; and the peritoneal cavity contained bloody serum. Dr. Hicks reports of the large tumour, that it was a mixture of cystic disease with fibrous matter; a large portion of the walls (say one-third) was formed of fibrous tissue, from a third of an inch to one inch thick. Between the cysts, the fibrous element was even more developed. The solid portion of the tumour weighed ten pounds; and about twenty-eight pints of serous fluid were removed by tapping during the operation.

\section{OBSTETRIC MEMORANDA.}

[UNDER this head, we shall, from time to time, as materials come to hand frorn correspondents, publish records of cases remarkable in themselves, or illustrating points of interest in obstetric practice, therapeutic or manipulative. We shall probably in this way preserve from ablivion the notes of very many useful and instructive occurrences in private practice; for the great obstetric experience is that-for the most part hitherto unwritten-of the great body of general practitioners throughout Great Britain. We will only ask those who may forward cases for record, to relate them with the utmost brevity, and equally to condense any appended remarks.]

\section{FATAL CARDIAC EFFUSION, OCCURRING ON THE NINTH DAY AFTER PARTURITION.}

By J. Waking-Curran, L.K.Q.C.P.I., etc., Bexhill, Hastings.

MRS. C., aged 22, the mother of one child, which had been born dead, was visited on September 2nd, of the present year. She presented that cadaverous waxy appearance, so characteristic of chlorosis, and was, according to her own calculation, at, or within a few days of, the period of her expected accouchement. Advice was sought, because of intense pain situated in, and considerable swelling of, her left thigh and leg. The œdema and pain evidently depended on the pressure of the gravid uterus on the neighbouring veins and nerves; accordingly the recumbent position was enjoined, and a simple saline with a belladonna liniment prescribed. Strong hope was entertained that, upon delivery, relief would be afforded to the distressing symptoms.

The belladonna allayed the pain when applied, but the swelling became so general and intense that the limb was anchylosed in the position, which, during a paroxysm of pain, the patient adopted as most alleviating; namely, the flexure of the thigh on the abdomen, the leg on the thigh, with the limb adducted, and the knee resting on its fellow of the opposite side. With no abatement, and little relief, the case continued until September 15th, when the woman was naturally and safely delivered of a well-nourished child, which event appeared to exercise a magic effect over the swollen member; for the moment pressure was taken off the impeded vessels, the pain ceased, the circulation became restored, and the swelling dispersed, so that in two days the leg could be perfectly straightened.
The patient progressed favourably up to the eighth day after delivery, when she complained of pain in deglutition, and general sore throat; on exploring the part, the velum pendulum appeared relaxed, but there was no inflammation of the tonsils, or surrounding parts, discernible. The next day, these symptoms disappeared; the woman was sitting up at the time of visit, and seemed herself again. In the night-time, however, owing to the sudden, unforeseen, and unusual occurrence of severe dyspnœa, immediate attendance was requested. On being visited, the patient was found propped with pillows, in the semi-erect posture, unable to lie on the back, with great distress in breathing, visible pulsation of carotids, and a pulse beating 120 in the minute. The more distressing symptoms yielded to the application of mustard over the chest, and a mixture of lobelia and Hoffman's anodyne solution. On carefully examining the chest, the day following, I remarked the impulse of the heart, though normal in action, preternaturally accelerated in motion, and stethoscopically I recognised the first sound of the heart cloaked, and accompanied by a soft bellows-murmur, best audible at the apex, and over the central piece of the sternum. The second sound was clear, distinct, and unaccentuated. There was increased dulness occupying the posterior and inferior part of the cardiac region. The countenance pourtrayed the anxious, and distressing features characteristic of pericardial or endocardial inflammation; but, notwithstanding a most careful stethoscopic research, there was no friction-sound audible. There were jugular pulsation, and fits of dyspnœea occurring at intervals; pulse I 30 ; and respiratory acts 29 per minute.

The following day there was a serious increase of cardiac dulness ; both sounds of the heart were masked; the heart's action was irregular and tumultuous, and the dyspnœa still more distressing and constant. Tthroughout the day, and towards evening especially, the breathing became more complicated, the circulation more embarrassed, and the patient when in the act of turning in the bed, about an hour after the evening visit, " to rest" herself, as she said, suddenly died. Movement or excitement had been rigidly directed to be guarded against.

The murmur I look upon as a functional systolic mitral one, which I had hoped would have yielded to mild counter-irritation, and the administration of ferruginous tonics; for the sudden effusion I was unprepared, but not for the consequence when once it manifested itself in such a patient, and at such a time. The hydrops pericardii I believe to have been owing to, and solely depending on, without the slightest inflammatory lesion, an originally impoverished condition of blood, whose leukocythæmic tendency, (as Dr. Bennett would very properly say) was accelerated by the debilitating discharges consequent on child-birth.

\section{EFFECTS OF MENTAL SHOCK UPON THE FETUS IN THE FIFTH MONTH OF PREGNANCY.}

By T. H. Graham, M.R.C.S. \& L.A.C., Lamberhurst, Kent.

M. B., aged 35, a labourer's wife, mother of seven children, in the fifth month of pregnancy, was feeding some rabbits, when one of them jumped out of the hutch with its eye glaring upon her, causing a sudden fright ; and, although a strong-minded woman (to use her own words), she could not get the glare of the rabbit's eyes out of her thoughts, and she was convinced that there would be something wrong with the child when it was born.

On the evening of June 27 th, I86-, I was sent for to come to this patient directly. I found labour had been progressing slowly for some hours; presentation natural. In about ten minutes after my arrival, three or four sharp forcing pains ruptured the membranes, giving escape to a very large quantity of licuor amnii; and the next pain brought a seven months' child into the world, presenting the following appearance. It had a hydrocephalic head, containing four ounces of serum. The face and mouth were small and rabbit-shaped. Instead of the nose, there was a fleshy growth three-fourths of an inch in length and a quarter of an inch in breadth, with a slight attachment to the nasal process of the frontal bone, and directed upwards at an angle of forty-five degrees. The space between the above process and the mouth was occupied by a body resembling an adult grown eye, with upper and lower lids; and within this were two small eyes, moving freely about during the short period that life lasted (ten minutes). There was but one optic nerve entering the sclerotica. On opening the latter, the aqueous humour escaped; and two crystalline lenses were found embedded in the vitreous humour, a quarter of an inch from each other, surrounded by the ciliary processes. There was no iris. From the occiput to the sacrum, the integument was covered with dark downy short hair. There were also the appearance known as spina bifida, and club-feet. The child was $15 \frac{3}{4}$ inches in height, and weighed four pounds. The woman recovered her strength very quickly,"and has since been delivered of two full-grown healthy children. 